\title{
The Association between Endogenous Hair Steroid Hormones and Social Environmental Factors in a Group of Conscripts during Basic Military Training
}

\author{
Asta Mažeikienè ${ }^{1, * \mathbb{D}}$, Svajone Bekesiene ${ }^{2, * \mathbb{D}}$, Dovilè Karčiauskaitė ${ }^{1}$, Eglè Mazgelyte் ${ }^{1}$ (D), Gerry Larsson ${ }^{1,3,4}$, \\ Tomas Petrènas ${ }^{5}$, Andrius Kaminskas ${ }^{5}$, Jurgita Songailienè ${ }^{5}$, Algirdas Utkus ${ }^{5}$, Ramutè Vaičaitienè ${ }^{2}$ and \\ Rasa Smaliukiené 2 (D)
}

Citation: Mažeikienè, A.; Bekesiene, S.; Karčiauskaitè, D.; Mazgelytè, E.; Larsson, G.; Petrènas, T.; Kaminskas, A.; Songailienè, J.; Utkus, A.; Vaičaitienè, R.; et al. The Association between Endogenous Hair Steroid Hormones and Social Environmental Factors in a Group of Conscripts during Basic Military Training. Int. J. Environ. Res. Public Health 2021, 18, 12239. https://doi.org/10.3390/ ijerph182212239

Academic Editors: Luana Main and Jamie Tait

Received: 23 September 2021 Accepted: 16 November 2021 Published: 22 November 2021

Publisher's Note: MDPI stays neutral with regard to jurisdictional claims in published maps and institutional affiliations.

Copyright: () 2021 by the authors Licensee MDPI, Basel, Switzerland. This article is an open access article distributed under the terms and conditions of the Creative Commons Attribution (CC BY) license (https:/ / creativecommons.org/licenses/by/ $4.0 /)$.
1 Department of Physiology, Biochemistry, Microbiology and Laboratory Medicine, Institute of Biomedical Sciences, Faculty of Medicine, Vilnius University, LT-03101 Vilnius, Lithuania; dovile.karciauskaite@mf.vu.lt (D.K.); egle.mazgelyte@mf.vu.lt (E.M.); gerry.larsson@fhs.se (G.L.)

2 General Jonas Zemaitis Military Academy of Lithuania, LT-10322 Vilnius, Lithuania; ramute.vaicaitiene@lka.lt (R.V.); rasa.smaliukiene@lka.lt (R.S.)

3 Department of Security, Strategy and Leadership (ISSL), Swedish Defence University, 65180 Karlstad, Sweden

4 Department of Public Health, Inland Norway University of Applied Sciences, 2418 Elverum, Norway

5 Department of Human and Medical Genetics, Institute of Biomedical Sciences, Faculty of Medicine, Vilnius University, LT-03101 Vilnius, Lithuania; tomas.petrenas@santa.lt (T.P.); andrius.kaminskas@santa.lt (A.K.); jurgita.songailiene@mf.vu.lt (J.S.); algirdas.utkus@mf.vu.lt (A.U.)

* Correspondence: asta.mazeikiene@mf.vu.lt (A.M.); svajone.bekesiene@lka.lt (S.B.)

\begin{abstract}
This study aimed to analyse the association between endogenous hair steroid hormones as reliable biological indicators of an individual's stress level and the social environmental factors experienced during military training that are manifested at the beginning of compulsory military service. Hair steroid hormone concentrations-cortisol, cortisone, dehydroepiandrosterone (DHEA), and testosterone-in a group of 185 conscripts were measured using the ultra-high performance liquid chromatography-tandem mass spectrometry method. Six subjective social environmental factors in the military - attitude towards the military and military service, adaptation to the military environment, team, task, and norm cohesion, as well as psychological (un)safety in the group-were evaluated using military-specific research questionnaires. Weak but significant negative correlations were identified between cortisol and adaptation $(\mathrm{r}=-0.176, p<0.05)$, attitude $(\mathrm{r}=-0.147, p<0.05)$ as well as between testosterone and task cohesion $(\mathrm{r}=-0.230, p<0.01)$ levels. Additionally, a multiple forward stepwise regression analysis highlighted that cortisone variation might be partially explained by task cohesion; the DHEA-determined by psychological (un)safety in the group, attitude towards the military and military service, and norm cohesion; and the testosterone-determined by task cohesion and adaptation to the new military environment. The results of this study suggest that subjective measures of social factors can be used to predict hair steroid hormone levels as objective measures of the chronic stress perceived by conscripts during their basic military training.
\end{abstract}

Keywords: hair steroid hormones; cortisol; cortisone; dehydroepiandrosterone; testosterone; military conscripts; military training social environmental factors; chronic stress biomarkers

\section{Introduction}

There is growing evidence to show that chronic stress, which is caused by social, environmental, and occupational stressors, can severely affect individual wellbeing. In a military context, stressors can come in various forms, including physical and psychological stressors [1]. During compulsory military service, especially in the early stages, conscripts cope with multiple military training social environmental factors [2] such as adjusting to a new military environment, group cohesion, and psychological unsafety, all of which can affect the psychological and physical response in cases that involve unsuccessful or 
prolonged adaptation, serving as sources of occupational stress. Conducting research into such an environment may provide new insights in terms of better understanding how human hormones respond to external stressors. To avoid stress-induced negative consequences, stress management programmes may be needed. However, a primary requirement for developing effective interventions is identifying reliable biological indicators in an individual's stress levels.

The hypothalamic-pituitary-adrenal (HPA) axis represents the central stress response system. Stressors come in many types, including social and physical stressors, but all types activate the HPA axis via different pathways [3]. The stress response involves bidirectional communication between the brain and other body systems via neural and endocrine mechanisms [4] and, consequently, can lead to changes in the level of many hormones [5], which may be used in the evaluation of stress levels. The major limitation of blood, salivary, or urine hormone measurements is the rapid daily concentration fluctuations [6,7]. Although the mechanism that involves hormone incorporation into the hair is not fully understood, the measurement of hormone levels in scalp hair is considered a promising non-invasive technique in chronic stress evaluation [7-9]. The analysis of steroid hormones in hair is increasingly being used in stress-related research in order to obtain retrospective data on hormone secretion [10,11]. Cortisol, an end-product of the HPA axis, is considered the primary hormone in a stress response mechanism [12-14]. However, HPA axis responses can also be affected by steroid hormones such as dehydroepiandrosterone (DHEA) or testosterone $[15,16]$. DHEA, a precursor of the sex hormone testosterone, and cortisol are the most abundant human adrenal hormones. Together, they tightly coordinate short-term and long-term endocrine stress responses, while also empowering the physiological and behavioural adjustments that are necessary for maintaining homeostasis [17]. Cortisol and DHEA with testosterone have an inverse relationship: while cortisol stimulates, testosterone and its precursor, DHEA, tend to limit the stress response [18,19]. DHEA also facilitates the metabolism of cortisol to the inactive metabolite cortisone [20]. The cortisone concentration in hair has been less well studied; however, it can provide comprehensive information on the cumulative amount of glucocorticoids in the body [21].

The majority of chronic stress studies, including military-related research, have been directed towards the evaluation of hair cortisol levels $[13,14,22,23]$. The results of many studying focusing on military veterans or active-duty soldiers deployed to war zones support the usefulness of hair cortisol as a biobehavioral marker of chronic stress: hair cortisol levels highly correlate with posttraumatic stress disorder (PTSD) symptom scores [24], and it was found to be predictive of a more significant increase in PTSD symptomatology in soldiers who had experienced new-onset traumatic events [25]. However, the hair cortisol concentration was reported to be unaffected by basic military training, while military training was perceived as stressful but not as a severe life event. [26]. Moreover, no clear relationship exists between perceived stress and hair cortisol [26,27]. Meanwhile, social environmental factors that are present during the military training that conscripts undertake are assumed to have an effect on perceived stress levels. Previous studies indicate adaptability as an important factor to the stress levels of conscripts [28]. It also has been shown that group cohesion can help to reduce negative stress reactions [29]. However, there have been not studies that have focused on a relationship between social environmental factors during the military training that conscripts undergo and biomedical outcome measures such as stress hormones and the data on hair steroid hormones other than cortisol. The analysis of multiple hair steroid hormone concentrations may provide more precise information on long-term stress exposure, while analysis on an association between hair steroid hormones and the subjective factors of social environment manifested at the beginning of compulsory military service may provide information about the missing linkage between perceived stressors and body hormonal reaction.

The above-mentioned findings lead to the hypothesis that hair steroid hormones are associated with military training social environmental factors and can be used as markers to identify the chronic stress levels of conscripts. The aim of this study was to evaluate 
concentrations of the major hair steroid hormones: cortisol, cortisone, testosterone, and DHEA, and to identify trends in the association between hair steroid hormone levels and the social environmental factors that are encountered during military training, such as adaptation, cohesion, and psychological (un)safety in the group, and the attitude towards military service amongst military conscripts. Our findings consider a portfolio of stressrelated factors and contribute towards the expanding knowledge of the factors that affect hair steroid hormone levels.

\section{Materials and Methods}

\subsection{Study Participants and Data Collection}

The open-access program OpenEpi, (version 3.01) was used to calculate the study sample size. After selecting the research significance level alpha $=0.05$ and the research power $-80 \%$, the preliminary size of the research sample was estimated. The chronic stress prevalence parameter was assumed to be $50 \%$, as the exact prevalence of this indicator in the study population is unknown. As such, this cross-sectional study included a random sample of 185 male conscripts who were aged between eighteen and twenty-six years. During the recruitment process, the conscripts were evaluated to be mentally and physically healthy and, therefore, the study participants represent a sample of healthy young men. Exclusion criteria included the use of synthetic steroids during over the previous three months. The basic characteristics of the study group are presented in Table 1.

Table 1. Anthropometric values and lifestyle details of the study participants.

\begin{tabular}{ll}
\hline \multicolumn{1}{c}{ Characteristic } & \multicolumn{1}{c}{ Value } \\
\hline Age (years), median (IQR) & $20.32(1.61)$ \\
\hline Education, n (\%) & $10(5.3)$ \\
Unfinished secondary & $134(71.4)$ \\
Secondary & $29(17.0)$ \\
Vocational school & $12(6.4)$ \\
Higher education (university or non-university) & $183.19(7.07)$ \\
Height (m), mean (SD) & $79.79(11.79)$ \\
Weight (kg), mean (SD) & $24.00(16)$ \\
Body mass index (kg/m $\left.{ }^{2}\right)$, median (IQR) & $0.84(1.04)$ \\
Waist-to-hip ratio, median (IQR) & \\
\hline Smoking status, n (\%) & $78(42.0)$ \\
Yes & $48(26.0)$ \\
Occasionally & $59(32.0)$ \\
No & $3(1.6)$ \\
Yes & $182(98.4)$ \\
No & $3(1.2)$ \\
Hair dyeing over last three months, $\mathrm{n}(\%)$ & $61(33.1)$ \\
Once a week or less & $121(65.7)$ \\
Between 2-4 times a week & \\
Five times a week and more &
\end{tabular}

Notes: descriptive statistics of normally distributed quantitative measures have been described using mean and standard deviation (SD), while non-normally distributed variables were presented as median and interquartile range (IQR).

The study was approved by the Vilnius Regional Biomedical Research Ethics Committee (protocol No. 2020/10-1275-754). Informed written consent was obtained from all of the participants who were in volved in the study. There was no reimbursement provided for participations. Participants were informed about the possibility of withdrawing from the study at any point. 
The information was collected from two battalions of the Lithuanian Armed Forces in November 2020 and August 2021 using two pools of the conscripts from the autumn and spring calls for compulsory military service to avoid the effect of seasonality in the study. The data were collected during the COVID-19 pandemic, specifically in November 2020 and in August 2021, when additional restrictions were being enforced in line with health safety guidelines. The assessments were conducted after the first month of military service. The first months of service are designed for the conscripts to gain basic military skills (practicing with military equipment on the fixed installation and the field exercises); they compose the first part of the nine-month-duration conscription service in Lithuania. During this period, conscripts adapt to the military environment, i.e., to a military order and military team (squad), as well as increase their physical capacity through individual physical training.

Each enrolled individual was asked to complete a set of questionnaires in order for their anthropometric and lifestyle characteristics to be analysed (including their age, education, and smoking status) along with military training social environmental factors. Hair samples were obtained by trained personnel so that tests could be carried out in terms of a steroid hormone concentration measurement and for the collection of anthropometric data (such as height and weight as well as waist and hip circumferences). Hair samples were collected from the posterior vertex region of the head, as close to the scalp as possible, and these samples were stored in foil at room temperature in a dark environment until the analysis could be carried out. Assuming an average hair growth rate of one centimeter per month, a collected one centimeter hair segment would contain steroid hormones deposited over the previous month. Hair steroid hormones analysis was conducted at the laboratories of the Institute of Biomedical Sciences, Faculty of Medicine, Vilnius University.

\subsection{Hair Steroid Hormones Analysis}

Hair steroid hormones (cortisol, cortisone, DHEA, and testosterone) were determined from the first centimetre of hair proximal to the scalp, representing approximately one month of growth before the hair was sampled. Hair washing and steroid hormone extraction procedures were carried out using the modified method proposed by Gao et al. [10]. A $20 \mathrm{mg}$ hair sample was washed by being gently shaken in $3 \mathrm{~mL}$ of isopropanol for three minutes at room temperature. Samples were allowed to dry under the fume hood for at least $24 \mathrm{~h}$. Then, $1.4 \mathrm{~mL}$ of methanol and $20 \mu \mathrm{L}$ of internal standard (cortisol-d4: $50 \mathrm{ng} / \mathrm{mL}$, cortisone-d8: $50 \mathrm{ng} / \mathrm{mL}$, DHEA-d6: $50 \mathrm{ng} / \mathrm{mL}$, testosterone-d3: $10 \mathrm{ng} / \mathrm{mL}$ ) were added, and the samples were incubated at $50{ }^{\circ} \mathrm{C}$ for four hours. The samples were centrifuged at $10,000 \mathrm{rpm}$ for five minutes, and the clear supernatant was transferred into the polypropylene tube. A stream of nitrogen gas was used for the evaporation of methanol and to dry the samples. The dry residue was re-suspended in $200 \mu \mathrm{L}$ of methanol/water containing $0.05 \%$ acetic acid at a ratio of 100:100 $(v / v)$. The chromatographic separation was carried out on the ultra-high performance liquid chromatography (UHPLC) system coupled with a triple quadrupole tandem mass spectrometer, which was equipped with an electrospray ionisation source and was operated in the positive ionisation mode. Two ion pairs were selected for each analyte, with the most sensitive transition being used for quantification and the rest being used for confirmation. A description of the UHPLC-MS/MS system (Shimadzu Corporation, Kyoto, Japan) and the analysis conditions are presented in Table 2. Data acquisition was conducted using the Shimadzu LabSolutions software (version 1.20). 
Table 2. Ultra-high performance liquid chromatography-tandem mass spectrometry (UHPLCMS/MS) system and analysis conditions.

\begin{tabular}{|c|c|}
\hline \multicolumn{2}{|c|}{ UHPLC-MS/MS System Components (Shimadzu Corporation, Kyoto, Japan) } \\
\hline \multicolumn{2}{|c|}{ Solvent delivery units (binary pumps) LC-30AD } \\
\hline \multicolumn{2}{|c|}{ Autosampler SIL-30AC } \\
\hline \multicolumn{2}{|c|}{ Column oven CTO-20AC } \\
\hline \multicolumn{2}{|c|}{ Triple quadrupole tandem mass spectrometer LCMS-8060 } \\
\hline \multicolumn{2}{|c|}{ UHPLC column YMC-Triart Bio C4 $(3.0 \times 100$ mm, $1.9 \mu \mathrm{m})$} \\
\hline \multicolumn{2}{|c|}{ Chromatographic separation conditions } \\
\hline Column temperature & $50{ }^{\circ} \mathrm{C}$ \\
\hline Mobile phase & $\begin{array}{l}\text { methanol and water acidified with } 0.05 \% \text { acetic acid } \\
\text { (binary gradient) }\end{array}$ \\
\hline Flow rate & $0.4 \mathrm{~mL} / \mathrm{min}$ \\
\hline Injection volume & $10 \mu \mathrm{L}$ \\
\hline
\end{tabular}

\subsection{Military Social Environment-Related Measures}

Military social environment-related measures were obtained using a military conscriptionspecific questionnaire. The items showed good reliability in the study sample: the calculated Cronbach's alpha coefficients for each item varied from 0.767 to 0.899 . The average variance extracted (AVE) and composite reliability (CR) indexes were analyzed to fit the validity of the military environment-related measures. All of the assessed AVE (ranging from 0.526 to 0.627 ) and $C R$ (ranging from 0.878 to 0.927 ) were considered. The final version of the questionnaire contained a total of forty-six questions, which served to measure six dimensions:

Attitude towards the military and military service (ATM): This is a six-item inventory that was designed to evaluate attitudes regarding the military in general. Attitude is a strong determinant of commitment as well as being a significant predictor of perceived stress [30]. The items in the inventory were determined based on the research by Salo [31] on Finnish conscript service, which aimed to measure how much military service made sense to the conscripts. Construct values vary in the interval from 6 to 42 , where a higher value indicates a more positive attitude towards military service. The calculated Cronbach's alpha was $0.811, \mathrm{CR}$ was 0.878 , and AVE was 0.574 .

Adaptation to the new military environment (ADJ): This forms a brief seven-item self-reporting inventory that was used to assess how effective the adaptation can be to the new environment. The items were taken from Salo [31]. They served to measure how conscripts got used to the new military environment and how conscripts adapted to the new military training environment when they were in an environment without their friends and family. Construct values vary in the interval from 7 to 49 , where a higher value indicates better adaptation. The calculated Cronbach's alpha was 0.872; CR was 0.909; and AVE was 0.590 .

Team cohesion (CTE): This is a twelve-item inventory that was designed to evaluate the relationships between squad members. It includes communications within a group, whether there is a desire to improve together, and how strong that desire might be. The measure was composed of multiple items that were taken from research by Salo [31] regarding Finnish conscript service, from the group cohesion scale that was revised by Treadwell et al. [32], and from research by Ohlsson et al. [33] on multinational military staff exercise. A sample item follows: "Squad soldiers feel comfortable in expressing disagreements within the group". Construct values vary in the interval from 12 to 84 , where a higher value indicates better team cohesion. The calculated Cronbach's alpha was 0.899; CR was 0.927; and AVE was 0.563.

Task cohesion (CTS): This is an eight-item inventory that was designed to evaluate the attitude of conscripts towards how effective their squads tend to be in terms of carrying out its assigned tasks, in sharing leadership, and in finding non-traditional ways to achieve 
the set goals. The items that were included in the research by Ohlsson et al. [33] regarding a multinational military staff exercise were adopted to the environment in which the conscripts found themselves. A sample item follows: "The quality of task performance which has been provided by this squad is improving over time". Construct values vary in the interval from 8 to 56 , where a higher value indicates better task cohesion. The calculated Cronbach's alpha was 0.767 ; CR was 0.898; and AVE was 0.526.

Norm cohesion (CIN): This is a six-item inventory that was designed to evaluate the existence of formal and informal rules within the squad and to discern any common tolerance in a group towards otherness, which would help in creating a positive environment. A sample item follows: "It would be a concern if the soldier did not take an active part in the squad's activities". Construct values vary in the interval from 6 to 42, where a higher value indicates better norm cohesion. The calculated Cronbach's alpha was 0.877; CR was 0.910; and AVE was 0.627.

Psychological (un)safety in the group (PSY): This is a seven-item inventory that was designed to evaluate marginalisation within the groups (squads). These negative items were taken from Salo [31] and Ohlsson et al. [33], and a sample item follows: "Other conscripts frequently ignore me". Construct values vary in the interval from 7 to 49 , where a lower value indicates a higher level of psychological safety. The calculated Cronbach alpha was 0.890; CR was 0.918; and AVE was 0.616.

All of the items were measured on a seven-point Likert scale. The research was conducted using printed questionnaires which were provided in the Lithuanian language.

\subsection{Statistical Analysis}

All statistical analyses were performed using the IBM SPSS Statistics $27 \mathrm{v}$ software. The Shapiro-Wilk test was used to determine if the data were distributed normally. Quantitative variables are presented as mean \pm standard deviation (SD) for normally distributed or median (interquartile range) (IQR) for non-normally distributed variables. For the categorical variables, the absolute and relative frequencies were calculated. The level of statistical significance was set at 0.05 for two-tailed testing.

Since the data collected for steroid hormone concentrations tend to violate the assumption of normality, the forward stepwise model selection method for automatic linear modelling (ALM) was chosen for the inferential statistical analysis [34,35]. The ALM procedure helped to avoid the collinearity issues that existed in all of the final designed models and to side-step the well-known limitations of the traditional regression procedure.

The statistical analysis, which was conducted through ALM building, used the hair steroid hormones (cortisol, cortisone, dehydroepiandrosterone, and testosterone) as the target or predictor variables in the separated models, and six variables were chosen as the predictors that served to assess the military social environment factors. Before the modelling process was undertaken, the auto data preparation side of things was completed, with a confidence level ninety-five percent was achieved. Then, the ALM procedure was carried out by means of the forward stepwise technique for model design [36]. In addition, use was made of Akaike's information criterion corrected (AICC) for the entry or elimination of possible predictors and to choose the most parsimonious model [36]. The importance of the predictors in the models was assessed in a stepwise fashion using incremental $R^{2}[37,38]$. Repeated analyses were conducted with the random seed of 54752075. Moreover, the validation of the designed models was conducted using the paired samples $t$-test between the measured and predicted data [39-41]. The automatic linear modelling analysis results as they concern the descriptions of the four designed models are summarised below in Section 3.2.

Four models were designed: Model 1 involved a prediction of the cortisol levels; Model 2 involved a prediction of the cortisone levels; Model 3 involved a prediction of the dehydroepiandrosterone levels; and Model 4 covered a prediction of the testosterone levels. The six military training social environment factors were used as predictor variables: attitude towards military service (ATM); adaptation to a new military environment 
(ADJ); team cohesion (CTE); task cohesion (CTS); norm cohesion (CIN); and psychological (un)safety in the group (PSY).

\section{Results}

Predictive models were constructed to clarify the hair steroid hormone levels (cortisol, cortisone, DHEA, and testosterone). The structure and accuracy testing for the constructed models is described in detail below, in Section 3.2. Additionally, the robustness-testing results for the established models are presented in Section 3.3.

\subsection{Preliminary Analysis}

The descriptive statistics of the stress-related variables is presented in Table 3.

Table 3. The descriptive analysis results for the gathered dataset.

\begin{tabular}{|c|c|c|c|c|c|c|c|c|c|}
\hline \multirow{3}{*}{ Variables $^{1}$} & \multicolumn{2}{|c|}{ Mean } & \multicolumn{3}{|c|}{ Dispersion } & \multicolumn{4}{|c|}{ Distribution } \\
\hline & \multirow{2}{*}{ Statistic } & \multirow{2}{*}{ Std Error } & \multirow{2}{*}{ Std Deviation } & \multirow{2}{*}{ Min } & \multirow{2}{*}{$\operatorname{Max}$} & \multicolumn{2}{|c|}{ Skewness } & \multicolumn{2}{|c|}{ Kurtosis } \\
\hline & & & & & & Statistic & Std Error & Statistic & Std Error \\
\hline CTL & 5.224 & 0.331 & 4.483 & 1.034 & 31.597 & 3.041 & 0.179 & 11.126 & 0.356 \\
\hline CTN & 16.847 & 0.554 & 7.518 & 3.233 & 48.204 & 1.818 & 0.179 & 4.008 & 0.356 \\
\hline DHEA & 13.860 & 0.851 & 11.541 & 2.912 & 77.368 & 3.203 & 0.179 & 12.182 & 0.356 \\
\hline TST & 0.645 & 0.039 & 0.528 & 0.143 & 4.133 & 3.324 & 0.179 & 14.672 & 0.356 \\
\hline ADJ & 35.380 & 0.667 & 9.047 & 10 & 49 & -0.719 & 0.179 & 0.112 & 0.356 \\
\hline ATM & 28.761 & 0.604 & 8.197 & 6 & 42 & -0.810 & 0.179 & 0.258 & 0.356 \\
\hline CTE & 61.935 & 0.958 & 12.995 & 22 & 84 & -0.643 & 0.179 & 0.227 & 0.356 \\
\hline CTS & 39.234 & 0.487 & 6.600 & 22 & 52 & -0.541 & 0.179 & -0.211 & 0.356 \\
\hline $\mathrm{CIN}$ & 31.870 & 0.567 & 7.697 & 8 & 42 & -0.987 & 0.179 & 0.509 & 0.356 \\
\hline PSY & 15.891 & 0.603 & 8.174 & 7 & 44 & 1.179 & 0.179 & 1.112 & 0.356 \\
\hline
\end{tabular}

${ }^{1}$ Valid N (listwise) = 184. Abbreviations used: cortisol (CTL), cortisone (CTN), dehydroepiandrosterone (DHEA), testosterone (TST), attitude towards the military service (ATM), adaptation to the new military environment (ADJ), team cohesion (CTE), task cohesion (CTS), norm cohesion (CIN), and psychological (un)safety in the group (PSY).

The following significant positive correlations were identified between the different indicators of military training social environmental factors: task cohesion and team cohesion $(\mathrm{r}=0.736, p<0.01)$; norm cohesion and team cohesion $(\mathrm{r}=0.577, p<0.01)$; team cohesion and attitude towards military service $(\mathrm{r}=0.540, p<0.01)$; and norm cohesion and task cohesion $(r=0.516, p<0.01)$. Significant negative correlations were identified between hair steroid hormone levels and the following military training social environmental factors: cortisol and adaptation to a new environment $(\mathrm{r}=-0.176, p<0.05)$ and cortisol and attitude towards military service $(\mathrm{r}=-0.147, p<0.05)$. Moreover, a significant negative correlation was identified between testosterone and task cohesion $(\mathrm{r}=-0.230$, $p<0.01)$. These variables were included in the modelling procedures. The relationships in the research variables are presented in Table 4.

Table 4. The relationship between hair steroid hormone levels and military training social environmental factors.

\begin{tabular}{|c|c|c|c|c|c|c|c|c|c|c|}
\hline & CTL & CTN & DHEA & TST & ADJ & ATM & CTE & CTS & CIN & PSY \\
\hline CTL & 1.000 & $0.726^{* *}$ & $0.388^{* *}$ & $0.306^{* *}$ & $-0.176^{*}$ & $-0.147^{*}$ & -0.108 & -0.117 & -0.123 & 0.103 \\
\hline CTN & $0.726 * *$ & 1.000 & $0.385^{* *}$ & $0.339 * *$ & -0.127 & -0.109 & -0.070 & -0.135 & -0.044 & 0.056 \\
\hline DHEA & $0.388^{* *}$ & $0.385^{* *}$ & 1.000 & $0.382 * *$ & -0.057 & 0.016 & -0.041 & -0.035 & -0.074 & 0.121 \\
\hline TST & $0.306^{* *}$ & $0.339 * *$ & $0.382^{* *}$ & 1.000 & 0.029 & -0.089 & -0.109 & $-0.230 * *$ & -0.110 & 0.127 \\
\hline ADJ & $-0.176^{*}$ & -0.127 & -0.057 & 0.029 & 1.000 & $0.480^{* *}$ & $0.361^{* *}$ & $0.396^{* *}$ & $0.445^{* *}$ & $-0.433^{* *}$ \\
\hline ATM & $-0.147^{*}$ & -0.109 & 0.016 & -0.089 & $0.480^{* *}$ & 1.000 & $0.540^{* *}$ & $0.484^{* *}$ & $0.358^{* *}$ & $-0.502 * *$ \\
\hline CTE & -0.108 & -0.070 & -0.041 & -0.109 & $0.361^{* *}$ & $0.540 * *$ & 1.000 & $0.736^{* *}$ & $0.577^{* *}$ & $-0.604^{* *}$ \\
\hline CTS & -0.117 & -0.135 & -0.035 & $-0.230 * *$ & 0.396 ** & $0.484^{* *}$ & $0.736^{* *}$ & 1.000 & $0.516^{* *}$ & $-0.557^{* *}$ \\
\hline CIN & -0.123 & -0.044 & -0.074 & -0.110 & $0.445^{* *}$ & $0.358 * *$ & $0.577 * *$ & 0.516 ** & 1.000 & $-0.608^{* *}$ \\
\hline PSY & 0.103 & 0.056 & 0.121 & 0.127 & $-0.433^{* *}$ & $-0.502 * *$ & $-0.604^{* *}$ & $-0.557 * *$ & $-0.608^{* *}$ & 1.000 \\
\hline
\end{tabular}

Note: Spearman's " $\mathrm{r}$ " correlation is significant at the $* p<0.05$ or $* * p<0.01$ level (a two-tailed test). Abbreviations used: cortisol (CTL), cortisone (CTN), dehydroepiandrosterone (DHEA), and testosterone (TST) attitude towards the military service (ATM), adaptation to the new military environment (ADJ), team cohesion (CTE), task cohesion (CTS), norm cohesion (CIN), psychological (un)safety in the group (PSY). 


\subsection{Automatic Linear Modelling Results}

All six military training social environmental factors were included in the forward stepwise linear regression analysis achieved by ALM modelling to discover which variables were the best predictors for hair steroid hormone levels. Additionally, the hair steroid hormones were included as predictors in the designed models where they were not chosen as a target variable.

\subsubsection{The Effects in the Constructed Models, and Building Steps}

Forward stepwise linear regression analysis was used to design the models. In the constructed models of all of the predictors were included, with the $p$-value effects being less than 0.05 and being removed with the effects when the $p$-value was greater than 0.1 . For the opportunity to be able to repeat the modelling analyses with the same settings, a random seed was set (a pseudo-random integer number, 54752075). The details of the effects and building steps being used in the constructed models with validation by AICC are presented in Table 5. Additionally, diagrams presenting the effects of the predictors for all of the constructed models can be found in the Back Matter of this paper (see Figures A1a-A4a in Appendix A).

Table 5. Forward stepwise model effects and validation by AICC description.

\begin{tabular}{|c|c|c|c|c|c|c|c|c|c|}
\hline \multirow{2}{*}{ Source } & \multirow{2}{*}{$\begin{array}{l}\text { Sum of } \\
\text { Squares }\end{array}$} & \multirow{2}{*}{ df } & \multirow{2}{*}{$\begin{array}{l}\text { Mean } \\
\text { Square }\end{array}$} & \multirow{2}{*}{$\mathbf{F}$} & \multirow{2}{*}{$p$} & \multicolumn{4}{|c|}{$\begin{array}{l}\text { Model Building Steps and } \\
\text { Validation by AICC }\end{array}$} \\
\hline & & & & & & 1 & 2 & 3 & 4 \\
\hline \multicolumn{10}{|c|}{ Model 1: Target $=$ Cortisol } \\
\hline Corrected Model & 1430.698 & 2 & 715.349 & 57.611 & 0.000 & 469.236 & 466.614 & - & - \\
\hline $\mathrm{CTN}$ & 951.591 & 1 & 951.591 & 76.637 & 0.000 & $\sqrt{ }$ & $\sqrt{ }$ & - & - \\
\hline DHEA & 58.011 & 1 & 58.011 & 4.672 & 0.032 & & $\sqrt{ }$ & - & - \\
\hline Residuals & 2247.439 & 181 & 12.417 & & & & & & \\
\hline Corrected total & 3678.138 & 183 & & & & & & & \\
\hline \multicolumn{10}{|c|}{ Model 2: Target = Cortisone } \\
\hline Corrected model & 5324.098 & 4 & 1331.025 & 47.731 & 0.000 & 627.452 & 620.991 & 617.747 & 614.314 \\
\hline CTL & 2877.989 & 1 & 2877.989 & 103.207 & 0.000 & $\sqrt{ }$ & $\sqrt{ }$ & $\sqrt{ }$ & $\sqrt{ }$ \\
\hline CTS & 158.801 & 1 & 158.801 & 5.695 & 0.008 & - & $\sqrt{ }$ & $\sqrt{ }$ & $\sqrt{ }$ \\
\hline DHEA & 152.771 & 1 & 152.771 & 5.478 & 0.020 & - & - & $\sqrt{ }$ & $\sqrt{ }$ \\
\hline TST & 95.613 & 1 & 95.613 & 3.429 & 0.066 & - & - & - & $\sqrt{ }$ \\
\hline Residuals & 4963.654 & 178 & 27.886 & & & & & & \\
\hline Corrected total & $10,287.752$ & 182 & & & & & & & \\
\hline \multicolumn{10}{|c|}{ Model 3: Target = DHEA } \\
\hline Corrected model & 4395.288 & 4 & 1098.822 & 9.833 & 0.000 & 877.001 & 872.618 & 869.959 & 868.334 \\
\hline PSY & 1189.803 & 1 & 1189.803 & 10.648 & 0.001 & $\sqrt{ }$ & $\sqrt{ }$ & $\sqrt{ }$ & $\sqrt{ }$ \\
\hline ATM & 537.447 & 1 & 537.447 & 4.810 & 0.030 & $\longrightarrow$ & $\sqrt{ }$ & $\sqrt{ }$ & $\sqrt{ }$ \\
\hline $\mathrm{CTN}$ & 459.050 & 1 & 59.050 & 4.108 & 0.044 & - & - & $\sqrt{ }$ & $\sqrt{ }$ \\
\hline CTL & 410.647 & 1 & 410.647 & 3.675 & 0.057 & - & - & - & $\sqrt{ }$ \\
\hline Residuals & $19,890.228$ & 178 & 111.743 & & & & & & \\
\hline Corrected total & $24,285.516$ & 182 & & & & & & & \\
\hline \multicolumn{10}{|c|}{ Model 4: target $=$ testosterone } \\
\hline Corrected model & 5.780 & 3 & 1.927 & 7.659 & 0.000 & -244.354 & -246.036 & -248.350 & - \\
\hline $\mathrm{CTN}$ & 2.879 & 1 & 2.879 & 11.441 & 0.001 & $\sqrt{ }$ & $\sqrt{ }$ & $\sqrt{ }$ & - \\
\hline CTS & 1.757 & 1 & 1.757 & 6.985 & 0.009 & - & $\sqrt{ }$ & $\sqrt{ }$ & - \\
\hline ADJ & 1.097 & 1 & 1.097 & 4.360 & 0.038 & - & - & $\sqrt{ }$ & - \\
\hline Residuals & 45.035 & 179 & 0.252 & & & & & & \\
\hline Corrected total & 50.815 & 182 & & & & & & & \\
\hline
\end{tabular}

Notes: Model $1=$ the response variable is cortisol; Model $2=$ the response variable is cortisone; Model $3=$ the response variable is dehydroepiandrosterone; Model $4=$ the response variable is testosterone; F = F-test statistic; $p=$ significance value; $\sqrt{ }=$ the variable which was included into the model at a specific step; AICC = the effect of the variable that was included into the model at a specific step. Abbreviations used: cortisol (CTL), cortisone (CTN), dehydroepiandrosterone (DHEA), and testosterone (TST) attitude towards the military service (ATM), adaptation to the new military environment (ADJ), team cohesion (CTE), task cohesion (CTS), norm cohesion (CIN), psychological (un)safety in the group (PSY). 
The F Statistics indicate that all four models have a high level of accuracy (see Model 1, Table 4). The model for cortisol (Model 1) revealed that cortisone and DHEA were the best predictors for cortisol levels (see Model 1, Table 5, AICC = 466.614). However, despite the preliminary analyses, a significant negative correlation was identified between cortisol levels and military training social environmental factors such as adaptation to a new military environment and attitude towards military service (see Table 4); these variables did not show any significant effects and were rejected from Model 1.

The model for cortisone (Model 2) revealed that four factors-cortisol, task cohesion, DHEA, and testosterone, showed the effects for an overall model (see Model 2, Table 5, AICC $=614.314$ ). Though task cohesion did not correlate with cortisone, it was included in the Model 2 training set in the second modelling step, and an important effect was identified upon the prediction of cortisone as a military training social environmental factor.

Two military training social environmental factors were chosen as the best predictors for the DHEA levels (Model 3), psychological (un)safety in the group (PSY) and attitude towards military service (see Model 3, Table 5, AICC = 868.334). It is important to reference the fact that the predictor psychological (un)safety in the group was included in the Model 3 training set in the first modelling step, and it identified a highly important effect upon DHEA prediction levels.

In the model for testosterone (Model 4), the significant effects were identified for three selected predictors. The significant F Statistics and the information criterion AICC $=-248.350$ revealed that cortisone and two military training social environmental factors-task cohesion and adaptation to a new military environment, were the best predictors for testosterone levels (see Model 4, Table 5).

\subsubsection{Coefficient and Predictor Importance in the Constructed Models}

Additionally, calculations were conducted to determine the standardised beta coefficient values, significance $t$ statistic tests, and 95\% confidence intervals for the individual model coefficients. All of the models are presented the same way: after the intercept the independent variable effects were organised from top to bottom by decreasing the predictor importance of each of the parameters that are included in the model (see Table 6). Additionally, within the predictors that contain effects, the coefficients are organised by the ascending order of data value. The calculated coefficients for Model 1, Model 2, Model 3, and Model 4 are presented in Table 6. Additionally, diagrams are presented for all of the constructed models (see Figures A1b-A4b in Appendix A).

Table 6. Calculated coefficients description for the designed models.

\begin{tabular}{|c|c|c|c|c|c|c|c|}
\hline \multirow{2}{*}{$\begin{array}{l}\text { Model } \\
\text { Name }{ }^{1}\end{array}$} & \multirow{2}{*}{$\begin{array}{c}\text { Coefficient } \\
\beta\end{array}$} & \multirow{2}{*}{$\begin{array}{c}\text { Std } \\
\text { Error } \beta\end{array}$} & \multirow{2}{*}{$\mathbf{t}$} & \multirow{2}{*}{$p$} & \multicolumn{2}{|c|}{ Confidence Interval 95\% } & \multirow{2}{*}{ Importance } \\
\hline & & & & & Lower & Upper & \\
\hline \multicolumn{8}{|c|}{ Model 1: Target = Cortisol } \\
\hline Intercept & -2.068 & 0.737 & -2.805 & 0.006 & -3.523 & -0.613 & \\
\hline CTN & 0.369 & 0.042 & 8.754 & 0.000 & 0.286 & 0.452 & 0.943 \\
\hline DHEA & 0.093 & 0.043 & 2.161 & 0.032 & 0.008 & 0.178 & 0.057 \\
\hline \multicolumn{8}{|c|}{ Model 2: Target $=$ Cortisone } \\
\hline Intercept & 12.285 & 2.828 & 4.344 & 0.000 & 6.704 & 17.866 & \\
\hline $\mathrm{CTL}^{1}$ & 1.455 & 0.143 & 10.159 & 0.000 & 1.173 & 1.738 & 0.806 \\
\hline CTS & -0.347 & 0.062 & -2.863 & 0.008 & -0.269 & -0.005 & 0.048 \\
\hline DHEA & 0.154 & 0.066 & 2.341 & 0.020 & 0.024 & 0.283 & 0.047 \\
\hline TST & 2.350 & 1.269 & 1.852 & 0.066 & -0.154 & 4.855 & 0.029 \\
\hline
\end{tabular}


Table 6. Cont.

\begin{tabular}{|c|c|c|c|c|c|c|c|}
\hline \multirow{2}{*}{$\begin{array}{l}\text { Model } \\
\text { Name }^{1}\end{array}$} & \multirow{2}{*}{$\begin{array}{c}\text { Coefficient } \\
\beta\end{array}$} & \multirow{2}{*}{$\begin{array}{c}\text { Std } \\
\text { Error } \beta\end{array}$} & \multirow[b]{2}{*}{$\mathbf{t}$} & \multirow{2}{*}{$p$} & \multicolumn{2}{|c|}{ Confidence Interval 95\% } & \multirow{2}{*}{ Importance } \\
\hline & & & & & Lower & Upper & \\
\hline \multicolumn{8}{|c|}{ Model 3: Target = DHEA } \\
\hline Intercept & -7.203 & 4.608 & -1.563 & 0.120 & -16.296 & 1.890 & \\
\hline PSY & 1.368 & 0.113 & 9.263 & 0.001 & 0.145 & 0.590 & 0.458 \\
\hline ATM & 0.233 & 0.106 & 2.193 & 0.030 & 0.023 & 0.443 & 0.207 \\
\hline CTN & 0.321 & 0.159 & 2.027 & 0.044 & 0.008 & 0.634 & 0.177 \\
\hline CTL & 0.672 & 0.350 & 1.917 & 0.057 & -0.020 & 1.363 & 0.158 \\
\hline \multicolumn{8}{|c|}{ Model 4: Target $=$ Testosterone } \\
\hline Intercept & 0.643 & 0.276 & 2.328 & 0.021 & 0.098 & 1.188 & \\
\hline CTN & 0.190 & 0.006 & 3.382 & 0.001 & 0.108 & 0.230 & 0.502 \\
\hline CTS & -0.107 & 0.006 & -2.643 & 0.009 & -0.129 & -0.004 & 0.307 \\
\hline ADJ & 0.100 & 0.005 & 2.088 & 0.038 & 0.091 & 0.209 & 0.191 \\
\hline
\end{tabular}

Notes: ${ }^{1}$ Model $1=$ the response variable is cortisol; Model $2=$ the response variable is cortisone; Model $3=$ the response variable is dehydroepiandrosterone; Model $4=$ the response variable is testosterone; $\beta=$ standardised beta coefficient; "Std error" $\beta=$ the standard error of the beta coefficient; $t=t$-test statistic; $p=$ significance value; "Importance" = the importance of the effect the variable is associated with the response/target variable Abbreviations used: cortisol (CTL), cortisone (CTN), dehydroepiandrosterone (DHEA), and testosterone (TST) attitude towards the military service (ATM), adaptation to the new military environment (ADJ), team cohesion (CTE), task cohesion (CTS), norm cohesion (CIN), and psychological (un)safety in the group (PSY).

\subsection{Robustness Testing for the Established Models}

The descriptive statistics for paired data samples in terms of the determined and predicted steroid hormone levels are presented in Table A1, Appendix B. A significant positive correlation was found between predicted cortisol levels $(\mathrm{r}=0.95, p<0.01)$, cortisone levels $(\mathrm{r}=0.95, p<0.01)$, dehydroepiandrosterone levels $(\mathrm{r}=0.95, p<0.01)$, and testosterone levels $(r=0.95, p<0.01)$ (see Table A2, Appendix B). The details for the paired samples $t$-test are presented in Table 7.

Table 7. Details of the conducted paired samples $t$-test so that differences can be assessed.

\begin{tabular}{ccccccccc}
\hline & \multicolumn{9}{c}{ Paired Differences } \\
\cline { 2 - 9 } Pair & \multirow{2}{*}{ Mean } & SD & \multirow{2}{*}{$\begin{array}{c}\text { Std Error } \\
\text { Mean }\end{array}$} & \multicolumn{2}{c}{ CI 95\% } & \multicolumn{3}{c}{$\boldsymbol{t}$-test } \\
\cline { 5 - 9 } & & & & Lower & Upper & $\mathbf{t}$ & df & $p$ \\
\hline Pair 1 & 0.129 & 2.233 & 0.165 & -0.196 & 0.454 & 0.785 & 183 & 0.434 \\
Pair 2 & -0.038 & 2.852 & 0.210 & -0.453 & 0.377 & -0.182 & 182 & 0.856 \\
Pair 3 & 0.137 & 7.854 & 0.581 & -1.009 & 1.282 & 0.235 & 182 & 0.814 \\
Pair 4 & 0.030 & 0.323 & 0.024 & -0.017 & 0.077 & 1.274 & 182 & 0.204 \\
\hline
\end{tabular}

Notes: Pair 1 measured cortisol levels and predicted levels in Model 1; Pair 2 measured cortisone levels and predicted levels in Model 2; Pair 3 measured dehydroepiandrosterone levels and predicted levels in Model 3; and Pair 4 measured testosterone levels and predicted levels in Model 4 . The 95\% CI referenced a 95\% confidence interval for the difference; the $t$-test relates to the student $t$-test; df denotes degrees of freedom; and $p$ represents for the statistical significance which is two-tailed tested.

The conducted $t$-test statistics for the paired samples verified the fact that there is no average difference between the measured cortisol levels and the predicted levels in Model $1\left(t_{183}=0.785, p=0.434\right)$, between the measured cortisone levels and the Model 2 predicted levels $\left(t_{182}=-0.182, p=0.856\right)$, between the measured dehydroepiandrosterone levels and the levels predicted by Model $3\left(t_{182}=0.235, p=0.814\right)$, or the measured testosterone levels and the figures that were predicted by Model $4\left(t_{182}=1.274, p=0.204\right)$.

According to the average of the determined and foreseen hair steroid hormone levels, it can be seen that the detected steroid levels are equivalent to the predicted levels as follows:

1. The measured cortisol levels were similar to the predicted levels in Model 1, with 95\% of a confidence interval $C I \in(-0.196,0.454)$; 
2. The measured cortisone levels were similar to the predicted levels in Model 2, with $95 \%$ of a confidence interval $\mathrm{CI} \in(-0.453,0.377)$;

3. The measured dehydroepiandrosterone levels were similar to the predicted levels in Model 3, with $95 \%$ of a confidence interval CI $\in(-1.009,1.282)$;

4. The measured testosterone levels were similar to the predicted levels in Model 4, with $95 \%$ of a confidence interval $C I \in(-0.07,0.077)$.

The outcomes from the applied $t$-test statistics for the paired samples proved the robustness of the designed models, with an insignificant difference between the measured and predicted data being observed.

\section{Discussion}

This study aimed to analyse the hormonal profile of the hair of conscripts in the early stages of their service while investigating the potential relationships with military training social environmental factors in order to identify the reliable biological indicators of an individual's stress level. The association between these objective and subjective measures is important to understand how the military social environment could be improved at the beginning of basic military training to avoid significant effects on hormone activation as a side effect of conscription service.

Our study used scalp hair analysis to evaluate steroid hormone levels rather than the more conventional methods such as serum, saliva, or urine measurements [7,9]. This method makes it possible to determine long-term steroid levels $[10,11]$ and eliminates any effect of daily hormone level fluctuations, especially in terms of the influence of stress, especially stress that has been caused by invasive sampling procedures [6,7]. In addition, it is essential to indicate the fact that scalp hair samples are easy to collect and are relatively stable [40].

Amongst other steroid hormones, hair cortisol is widely used as the primary biomarker of long-term exposure to chronic stress in a broad spectrum of psychoneuroendocrinological studies $[9,13,14]$. Increased hair cortisol levels were found in various contexts (e.g., endurance athletes [42-44], shift work [21], sleep and mental disorders [45], unemployment [46], chronic pain [47], or major life events [48]). Long-term elevations in serum [49] and hair cortisol [50] have been also reported during stressful military captivity training. Meanwhile, longitudinal research on basic military training at the beginning of military service reports controversial findings: in Boesh et al. [26], research on Swiss conscripts reports that basic military training has no effect on cortisol concentration, while Gifford et al. [50] conducted research on UK cadets and indicated an increase in the cortisol concentration during basic military training. Within the findings of our study, we can confirm an association between cortisol and external stress factors during military conscription: weak but significant negative correlations were observed between cortisol and individual adjustment to a new military environment $(\mathrm{r}=-0.176, p<0.05)$ as well as between cortisol and individual attitude towards military service $(r=-0.147, p<0.05)$, which indicates that long-term cortisol hypersecretion in youth emerges more from individual factors, such as adjustment and attitude, than it does from group cohesion factors (team, task, and norm cohesion).

An evaluation of a broader spectrum of hair steroid hormones levels, especially when sampled under low-stress conditions, should be something that is thought of as being debatable, as stress affects not only the activity of the hypothalamic-pituitary-adrenal axis but also the activity of the hypothalamic-pituitary-gonadal axis $[15,16]$. Despite this demand, to our knowledge, no studies of multiple hair steroid hormone concentrations in terms of correlations with subjective measures of social factors have yet been performed on military cohorts. Our research results indicate that other steroid hormones, such as hair cortisone, DHEA, and testosterone, which are not typically related to social environment and that have been identified as a primary biomarker of long-term exposure to chronic stress, can be explained by military training social environmental factors. Weak but significant negative correlations between testosterone levels and task cohesion $(\mathrm{r}=-0.230$, 
$p<0.01)$ indicate that variation in the testosterone level is linked to the group cohesion factor. Furthermore, by combining hormones and social environmental factors into one statistical model and applying an automatic linear modelling algorithm, it is confirmed that cortisone, DHEA, and testosterone levels can be explained by variation in the perceived social environmental factors during conscription to some extent. Task cohesion was identified as a marker for the prediction of lower hair cortisone levels (Model 2, CTS importance $=0.048$ ) and testosterone levels (Model 4, CTS importance $=0.307)$. Adjustment to a new military environment can also be a predictor for testosterone levels (Model 4, ADJ importance $=0.191$ ). Psychological (un)safety in the group (PSY) as well as attitude towards military service (ATM) were both recognised as significant markers for DHEA concentration levels (Model 3, PSY importance $=0.458$ and ATM importance $=0.207$ ) .

In order to explain these findings, the possibility of a bidirectional relationship between social factors and steroid hormones has to be taken into account. Subjectively perceived social factors influence individual hormonal response, and the steroid hormones modulate behavior through the corticosteroid receptors that are present in the brain. During the first month of basic military training, the conscript transitions from their home environment to a process of adjusting to military rules and regulations, acquiring a new skill set, building up a new network, and becoming part of a unit along the way [51]. Therefore, any interplay between individual military organisational factors and the biopsychosocial vulnerability of individuals may affect an individual's stress response, where it is coordinated through hormone action.

Similarly, the presence of increased DHEA in response to an acute psychosocial stressor [52] is something that has been found by other researchers. Acute stress lowers testosterone concentration, but on the whole, this is temporary [53-56] and can help one to adapt to stressful situations; on the other hand, lower levels of testosterone under conditions that involve chronic stress often correlate with a higher risk of PTSD [57,58]. However, with the exception of cortisol levels, the aforementioned findings come from studies that involve blood and saliva hormone measurements. There is a lack of research using human subjects that includes hair steroid hormone profiles when evaluating longterm stress exposure due to psychosocial factors. It is worth mentioning a result from the previous study that was conducted using laboratory mice, in which a higher level of DHEA - but not testosterone-was found in mice who had been housed in groups against those which had been housed in pairs [59]. This finding is in line with the fact that DHEA is a neuroactive steroid with action responses at several neurotransmitter receptors [60], indicating the importance of DHEA level evaluation in the psychosocial context.

The study was conducted during the peak of the COVID-19 pandemic, when military service was being organised in isolation from external contact. From that point of view, it is essential to point out the fact that some cultural or social support factors that would normally have allowed a conscript to be connected to friends or family were excluded during this period, so other military factors such as task cohesion or high levels of motivation to undertake one's service period became protective factors for stress accumulation. The main study strengths of the present study include the possibility of being able to eliminate the effect of non-military service-related stressors to a maximum along with validated scales with high levels of reliability and the automatic linear modelling procedure. An additional advantage in the use of this study was the fact that we were able to analyse hair steroid hormone levels using UHPLC-MS/MS. Liquid chromatography and tandem mass spectrometry is superior to immunoassays (IAs) for this purpose since despite sensitivity, cost, and simplicity, IAs include cross reactivity with similar analytes along with the existing standardisation issues between labs [61].

This study had several limitations. First, the absence of any female participants could be indicated as the main weakness of our study. Our results should be confirmed in more heterogeneous populations in order to generalise our findings across women or other age groups. Second, it is also essential to indicate that due to the abundance of modifications and a lack of standardised methodology [7] for the analysis of hair steroid hormone con- 
centrations, any interpretation of the results remains complicated. The same can be said about military training social environmental factors measurements. Due to the specifics of the conscription service and the limited accessibility to the conscript population, there are not many studies investigating conscription-specific social environmental factors and their effects. Furthermore, there are no standardized and cross-study validated tests to measure stress-related social environment factors in the military, such as adaptation to the military environment or elements of the conscripts' squad cohesion. In this study, we used questionnaires developed by previous researchers in their military and conscription studies, but this limits the compatibility of this research results with the research results obtained in other (non-military and non-military conscription) settings. Third, the cohort of military conscripts is specific because of the conclusory nature of the service; therefore, the interpretation of the results for another military cohort may be less comparable. Furthermore, due to the cross-sectional study design, we cannot determine the causality in the relationships between the hair steroid hormone levels and the military training social environmental factors.

\section{Conclusions}

The study revealed the significant effects of military training social environmental factors on hair cortisone, DHEA, and testosterone levels. Task cohesion, adaptation to a new military environment, psychological (un)safety in the group as well as attitude towards military and military service were shown to have a significant effect on hair steroid hormone levels in conscripts. These study findings suggest that cortisol could be considered as an objective biomarker for chronic stress that may be caused by compulsory conscript service and that cortisone, DHEA, and testosterone can also be included alongside it. Our study continues in terms of creating more precise modelling for chronic stress predictors, including the task of analyzing the ratios between individual hair steroid hormones in a longitudinal study.

Author Contributions: Conceptualisation, A.M., S.B., R.S. and D.K.; methodology, A.M., R.S., S.B., G.L., E.M., T.P., A.K., J.S., A.U. and D.K.; software, S.B.; validation by R.S., G.L., A.M., D.K. and S.B.; formal analysis, E.M., T.P. and A.K.; investigations, A.M., S.B., R.V., E.M., T.P., A.K., R.S. and D.K.; resources, R.S. and D.K.; data curation, R.S. and E.M.; writing for original draft preparation, A.M., S.B., R.S. and E.M.; writing for review and editing, A.M., S.B., R.S. and E.M.; visualisation, S.B.; supervision, J.S., A.U., D.K. and R.S.; project administration by R.S.; and funding acquisition by R.S. All authors have read and agreed to the published version of the manuscript.

Funding: This research was funded by the Research Council of Lithuania (LMTLT) under project agreement No S-MIP-20-59; the principal investigator for the grant was Rasa Smaliukienè.

Institutional Review Board Statement: The study was approved by the Vilnius Regional Biomedical Research Ethics Committee, protocol No 2020/10-1275-754.

Informed Consent Statement: Informed consent was obtained from all of those subjects who were involved in the study.

Data Availability Statement: The data supporting the reported results have been archived in the National Open Access Research Data Archive (MIDAS) at www.midas.lt, accessed on 10 November 2021.

Conflicts of Interest: The authors declare no conflict of interest. The funders had no role in the design of the study; in the collection, analyses, or interpretation of data; in the writing of the manuscript; or in the decision to publish the results. 


\section{Appendix A}

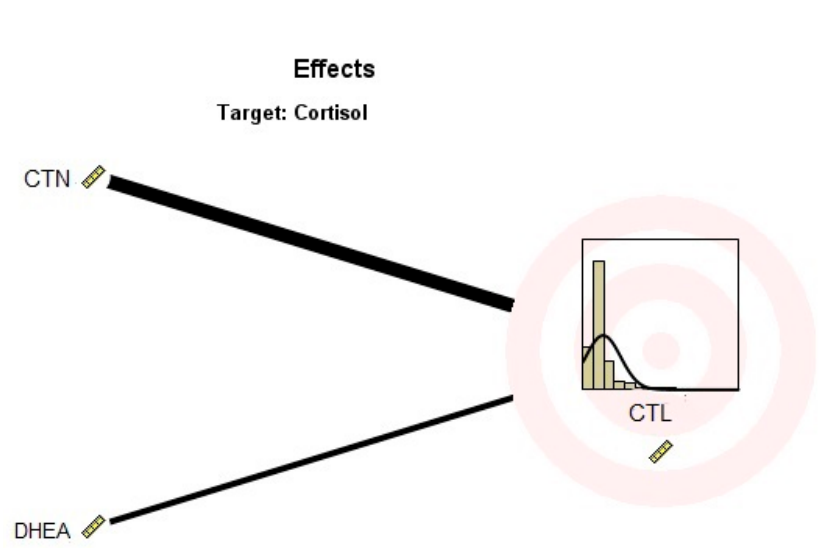

(a)

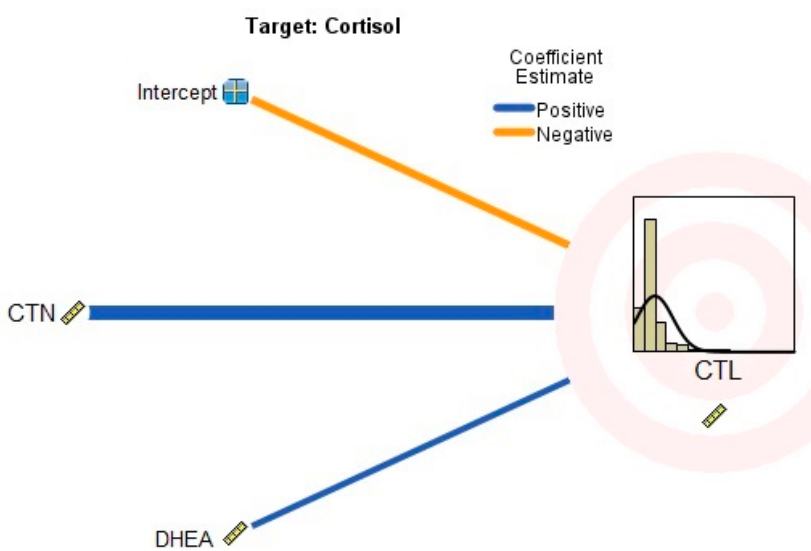

(b)

Figure A1. The forward stepwise model selection method results presented for Model 1 after automatic linear modelling: (a) the identified effects of the predictors on cortisol levels (CTL) by cortisone (CTN) and dehydroepiandrosterone (DHEA) and (b) the negative and positive coefficient estimations that were identified for cortisone (CTN) and dehydroepiandrosterone (DHEA) in Model 1.

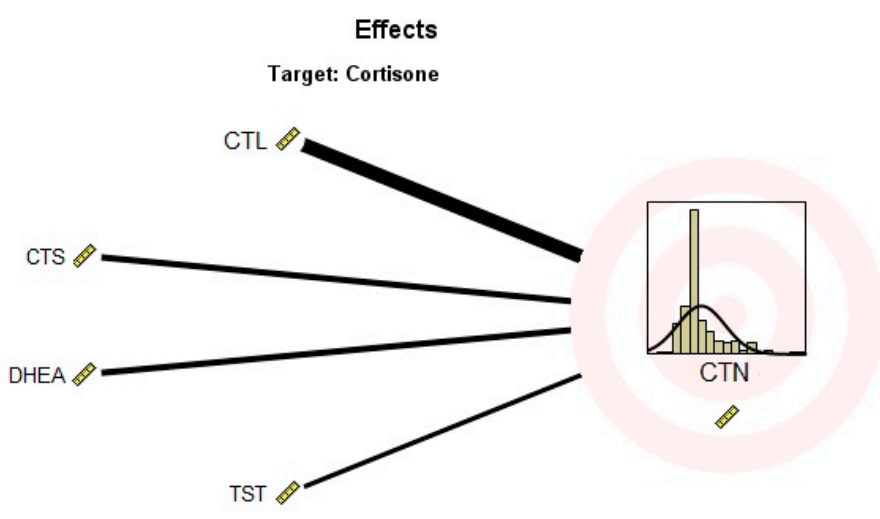

(a)

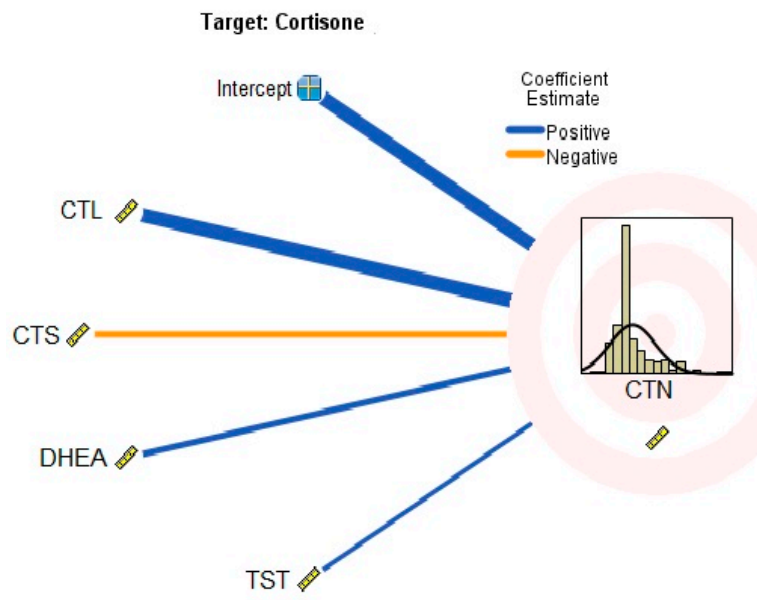

(b)

Figure A2. The forward stepwise model selection method results presented for Model 2 after automatic linear modelling: (a) the identified effects of the predictors on cortisone (CNT) levels by cortisol (CTL), task cohesion (CTS), dehydroepiandrosterone (DHEA), and testosterone (TST) and (b) the negative and positive coefficient estimations that were identified in Model 2 for cortisone (CNT) levels by cortisol (CTL), task cohesion (CTS), dehydroepiandrosterone (DHEA), and testosterone (TST). 


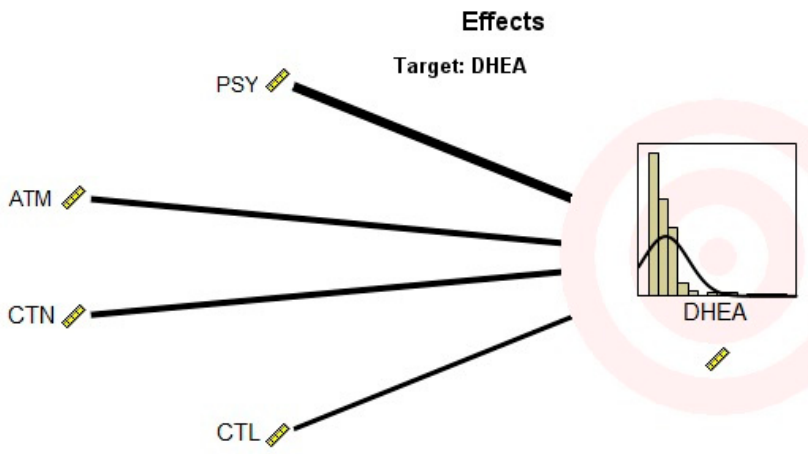

(a)

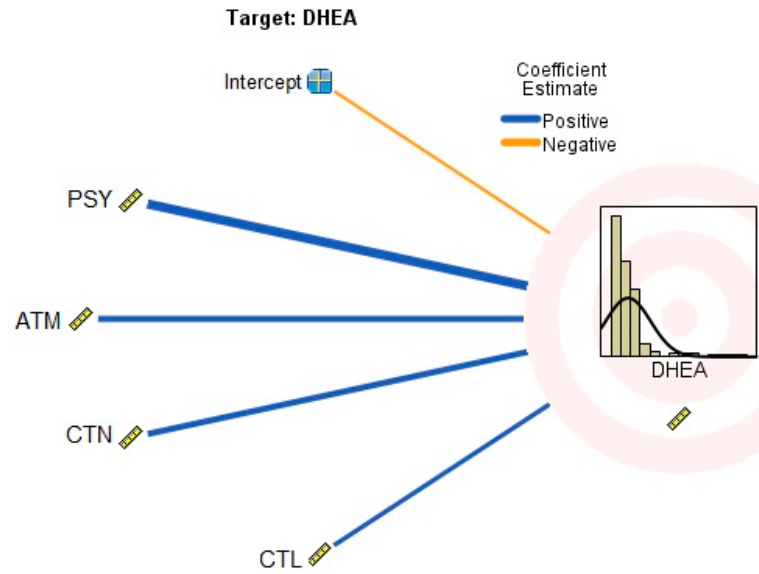

(b)

Figure A3. The forward stepwise model selection method results presented for Model 3 after automatic linear modelling: (a) the identified effects for the predictors on dehydroepiandrosterone levels (DHEA) by psychological (un)safety in the group (PSY), attitude towards the military service (ATM), cortisone (CTN), and cortisol (CTL) and (b) the negative and positive coefficient estimations that were identified in Model 3 for psychological (un)safety in the group (PSY), attitude towards the military service (ATM), cortisone (CTN), and cortisol (CTL).

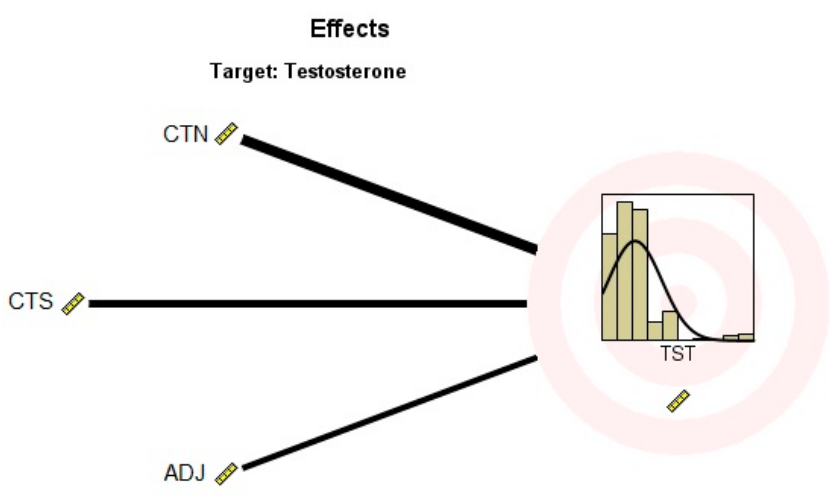

(a)

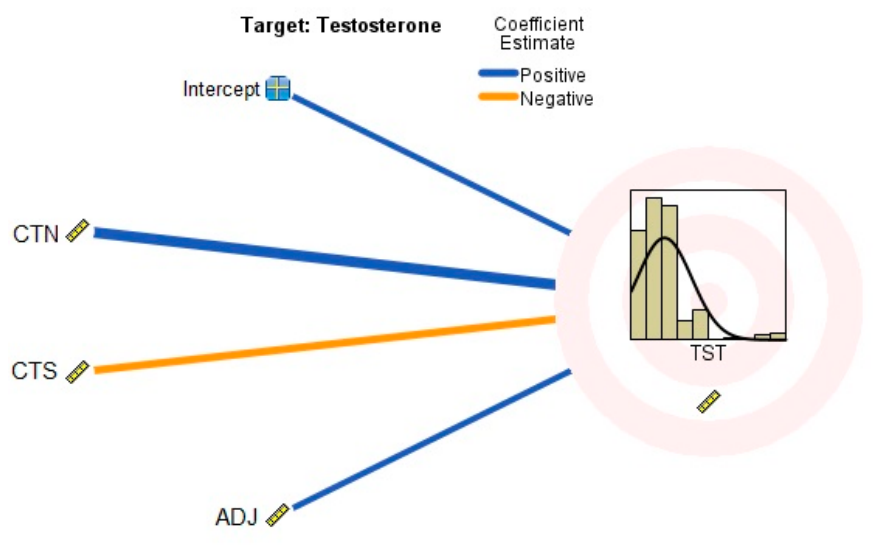

(b)

Figure A4. The forward stepwise model selection method results presented for Model 4 after automatic linear modelling: (a) the identified effects for the predictors on testosterone (TST) levels by cortisone (CTN), task cohesion (CTS), and adaptation to the new military environment (ADJ) and (b) the negative and positive coefficient estimations that were were identified in Model 4 for cortisone (CTN), task cohesion (CTS), and adaptation to the new military environment (ADJ).

\section{Appendix B}

Table A1. Paired samples statistics for measured and predicted levels of stress-related hormones.

\begin{tabular}{cccccc}
\hline \multicolumn{2}{c}{ Pairs Descriptions } & N & Mean & Std Error Mean & Std Deviation \\
\hline \multirow{2}{*}{ Pair 1 } & CTL & 183 & 5.224 & 0.331 & 4.483 \\
& Model 1 (CTL) & 183 & 5.354 & 0.244 & 3.316 \\
\hline \multirow{2}{*}{ Pair 2 } & CTN & 182 & 16.804 & 0.554 & 7.519 \\
& Model 2 (CTN) & 182 & 16.765 & 0.466 & 6.316 \\
\multirow{2}{*}{ Pair 3 } & DHEA & 182 & 13.911 & 0.854 & 11.551 \\
& Model 3 (DHEA) & 182 & 14.048 & 0.592 & 8.011 \\
\hline \multirow{2}{*}{ Pair 4 } & TST & 182 & 0.645 & 0.039 & 0.528 \\
& Model 4 (TST) & 182 & 0.675 & 0.029 & 0.390 \\
\hline
\end{tabular}

Notes: Pair 1 measured cortisol levels and predicted levels in Model 1 (CTL); Pair 2 measured cortisone levels and predicted levels in Model 2 (CTN); Pair 3 measured dehydroepiandrosterone levels and predicted levels in Model 3 (DHEA); Pair 4 measured testosterone levels and predicted levels in Model 4 (TST) levels. 
Table A2. Correlations of paired sample stress-related hormones.

\begin{tabular}{ccccc}
\hline \multicolumn{2}{c}{ Pairs Description } & N & Correlation Coefficient & $p$ \\
\hline Pair 1 & $\begin{array}{c}\text { CTL } \\
\text { Model 1 (CTL) }\end{array}$ & 184 & 0.878 & 0.000 \\
\hline Pair 2 & $\begin{array}{c}\text { CTN } \\
\text { Model 2 (CTN) }\end{array}$ & 183 & 0.930 & 0.000 \\
\hline Pair 3 & $\begin{array}{c}\text { DHEA } \\
\text { Model 3 (DHEA) }\end{array}$ & 183 & 0.734 & 0.000 \\
\hline Pair 4 & $\begin{array}{c}\text { TST } \\
\text { Model 4 (TST) }\end{array}$ & 183 & 0.793 & 0.000 \\
\hline
\end{tabular}

Notes: Pair 1 measured cortisol levels and predicted levels in Model 1 (CTL); Pair 2 measured cortisone levels and predicted levels in Model 2 (CTN); Pair 3 measured dehydroepiandrosterone levels and predicted levels in Model 3 (DHEA); Pair 4 measured testosterone levels and predicted levels in Model 4 (TST). $p=$ statistical significance two-tailed tested.

\section{References}

1. Pallavicini, F.; Argenton, L.; Toniazzi, N.; Aceti, L.; Mantovani, F. Virtual Reality Applications for Stress Management Training in the Military. Aerosp. Med. Hum. Perform. 2016, 87, 1021-1030. [CrossRef] [PubMed]

2. Purre, M.; Oja, L. Mental health in the military context: Emotional states and help-seeking behaviours during conscription. Am. Psychol. 2018, 6, 196-222.

3. Engelmann, M.; Landgraf, R.; Wotjak, C.T. The Hypothalamic-Neurohypophysial System Regulates the Hypothalamic-PituitaryAdrenal Axis under Stress: An Old Concept Revisited. Front. Neuroendocrinol. 2004, 25, 132-149. [CrossRef] [PubMed]

4. McEwen, B.S.; Gianaros, P.J. Central Role of the Brain in Stress and Adaptation: Links to Socioeconomic Status, Health, and Disease. Ann. N. Y. Acad. Sci. 2010, 1186, 190-222. [CrossRef]

5. Ranabir, S.; Reetu, K. Stress and Hormones. Indian J. Endocrinol. Metab. 2011, 15, 18-22. [CrossRef]

6. Ljubijankić, N.; Popović-Javorić, R.; Šćeta, S.; Šapčanin, A.; Tahirović, I.; Sofić, E. Daily Fluctuation of Cortisol in the Saliva and Serum of Healthy Persons. Bosn. J. Basic Med. Sci. 2008, 8, 110-115. [CrossRef] [PubMed]

7. Greff, M.J.E.; Levine, J.M.; Abuzgaia, A.M.; Elzagallaai, A.A.; Rieder, M.J.; van Uum, S.H.M. Hair Cortisol Analysis: An Update on Methodological Considerations and Clinical Applications. Clin. Biochem. 2019, 63, 1-9. [CrossRef]

8. Calamari, C.V.; Viau, P.; Nichi, M.; Martins, G.S.; Sobral, G.; Mangueira Dias, J.H.; de Oliveira, C.A. Hair as an Alternative Noninvasive Matrix: Sources of Variation in Testosterone Levels. Domest. Anim. Endocrinol. 2020, 72, 106477. [CrossRef]

9. El-Farhan, N.; Rees, D.A.; Evans, C. Measuring Cortisol in Serum, Urine and Saliva-Are Our Assays Good Enough? Ann. Clin. Biochem. 2017, 54, 308-322. [CrossRef]

10. Gao, W.; Stalder, T.; Foley, P.; Rauh, M.; Deng, H.; Kirschbaum, C. Quantitative Analysis of Steroid Hormones in Human Hair Using a Column-Switching LC-APCI-MS/MS Assay. J. Chromatogr. B 2013, 928, 1-8. [CrossRef]

11. Noppe, G.; de Rijke, Y.B.; Dorst, K.; van den Akker, E.L.T.; van Rossum, E.F.C. LC-MS/MS-Based Method for Long-Term Steroid Profiling in Human Scalp Hair. Clin. Endocrinol. 2015, 83, 162-166. [CrossRef]

12. Russell, E.; Koren, G.; Rieder, M.; Van Uum, S. Hair Cortisol as a Biological Marker of Chronic Stress: Current Status, Future Directions and Unanswered Questions. Psychoneuroendocrinology 2012, 37, 589-601. [CrossRef]

13. Voegel, C.D.; Hofmann, M.; Kraemer, T.; Baumgartner, M.R.; Binz, T.M. Endogenous Steroid Hormones in Hair: Investigations on Different Hair Types, Pigmentation Effects and Correlation to Nails. Steroids 2020, 154, 108547. [CrossRef]

14. Staufenbiel, S.M.; Penninx, B.W.J.H.; Spijker, A.T.; Elzinga, B.M.; van Rossum, E.F.C. Hair Cortisol, Stress Exposure, and Mental Health in Humans: A Systematic Review. Psychoneuroendocrinology 2013, 38, 1220-1235. [CrossRef] [PubMed]

15. Guo, L.; Chen, Y.-X.; Hu, Y.-T.; Wu, X.-Y.; He, Y.; Wu, J.-L.; Huang, M.-L.; Mason, M.; Bao, A.-M. Sex Hormones Affect Acute and Chronic Stress Responses in Sexually Dimorphic Patterns: Consequences for Depression Models. Psychoneuroendocrinology 2018, 95, 34-42. [CrossRef] [PubMed]

16. Choi, J.C.; Chung, M.I.; Lee, Y.D. Modulation of Pain Sensation by Stress-Related Testosterone and Cortisol. Anaesthesia 2012, 67, 1146-1151. [CrossRef] [PubMed]

17. Kamin, H.S.; Kertes, D.A. Cortisol and DHEA in Development and Psychopathology. Horm. Behav. 2017, 89, 69-85. [CrossRef]

18. Boudarene, M.; Legros, J.J.; Timsit-Berthier, M. Study of the stress response: Role of anxiety, cortisol and DHEAs. Encephale 2002, 28, 139-146.

19. Pasquali, R. The Hypothalamic-Pituitary-Adrenal Axis and Sex Hormones in Chronic Stress and Obesity: Pathophysiological and Clinical Aspects. Ann. N. Y. Acad. Sci. 2012, 1264, 20-35. [CrossRef]

20. van Zuiden, M.; Haverkort, S.Q.; Tan, Z.; Daams, J.; Lok, A.; Olff, M. DHEA and DHEA-S Levels in Posttraumatic Stress Disorder: A Meta-Analytic Review. Psychoneuroendocrinology 2017, 84, 76-82. [CrossRef]

21. Zhang, Y.; Shen, J.; Zhou, Z.; Sang, L.; Zhuang, X.; Chu, M.; Tian, T.; Xiao, J.; Lian, Y. Relationships among Shift Work, Hair Cortisol Concentration and Sleep Disorders: A Cross-Sectional Study in China. BMJ Open 2020, 10, e038786. [CrossRef] [PubMed] 
22. Jewgenow, K.; Azevedo, A.; Albrecht, M.; Kirschbaum, C.; Dehnhard, M. Hair Cortisol Analyses in Different Mammal Species: Choosing the Wrong Assay May Lead to Erroneous Results. Conserv. Physiol. 2020, 8, coaa009. [CrossRef] [PubMed]

23. Cattet, M.; Macbeth, B.J.; Janz, D.M.; Zedrosser, A.; Swenson, J.E.; Dumond, M.; Stenhouse, G.B. Quantifying Long-Term Stress in Brown Bears with the Hair Cortisol Concentration: A Biomarker That May Be Confounded by Rapid Changes in Response to Capture and Handling. Conserv. Physiol. 2014, 2, cou026. [CrossRef]

24. Groer, M.W.; Kane, B.; Williams, S.N.; Duffy, A. Relationship of PTSD Symptoms With Combat Exposure, Stress, and Inflammation in American Soldiers. Biol. Res. Nurs. 2015, 17, 303-310. [CrossRef]

25. Steudte-Schmiedgen, S.; Stalder, T.; Schönfeld, S.; Wittchen, H.-U.; Trautmann, S.; Alexander, N.; Miller, R.; Kirschbaum, C. Hair Cortisol Concentrations and Cortisol Stress Reactivity Predict PTSD Symptom Increase after Trauma Exposure during Military Deployment. Psychoneuroendocrinology 2015, 59, 123-133. [CrossRef]

26. Boesch, M.; Sefidan, S.; Annen, H.; Ehlert, U.; Roos, L.; Van Uum, S.; Russell, E.; Koren, G.; La Marca, R. Hair Cortisol Concentration Is Unaffected by Basic Military Training, but Related to Sociodemographic and Environmental Factors. Stress 2015, 18, 35-41. [CrossRef]

27. Wester, V.L.; Rossum, E.F.C. van. Clinical Applications of Cortisol Measurements in Hair. Eur. J. Endocrinol. 2015, 173, M1-M10. [CrossRef]

28. Tucker, J.S.; Gunther, K.M. The Application of a Model of Adaptive Performance to Army Leader Behaviors. Mil. Psychol. 2009, 21, 315-333. [CrossRef]

29. Driskell, T.; Driskell, J.E.; Salas, E. Mitigating Stress Effects on Team Cohesion. In Team Cohesion: Advances in Psychological Theory, Methods and Practice; Research on Managing Groups and Teams; Emerald Group Publishing Limited: Bingley, UK, 2015; Volume 17, pp. 247-270. [CrossRef]

30. Bernhard, C.; Sverke, M. Work attitudes, role stress and health indicators among different types of contingent workers in the Swedish health care sector. Res. Pract. Hum. Resour. Manag. 2003, 11, 1-16.

31. Salo, M. Determinants of Military Adjustment and Attrition during Finnish Conscript Service. Ph.D. Thesis, University of Tampere, Helsinki, Finland, 2008.

32. Treadwell, T.; Lavertue, N.; Kumar, V.K.; Veeraraghavan, V. The Group Cohesion Scale-Revised: Reliability and validity. Int. J. Action Methods Psychodrama Ski. Train. Role Play. 2001, 54, 3-12.

33. Bekesiene, S.; Hoskova-Mayerova, S.; Diliunas, P. Structural Equation Modeling Using the Amos and Regression of Effective Organizational Commitment Indicators in Lithuanian Military Forces. In Proceedings of the Aplimat-16th Conference on Applied Mathematics, Bratislava, Slovak, 31 January-2 February 2017; pp. 91-102.

34. Bekesiene, S.; Hošková-Mayerová, Š.; Diliunas, P. Identification of Effective Leadership Indicators in the Lithuania Army Forces. In Mathematical-Statistical Models and Qualitative Theories for Economic and Social Sciences; Hošková-Mayerová, Š., Maturo, F., Kacprzyk, J., Eds.; Studies in Systems, Decision and Control; Springer: Cham, Switzerland, 2017; Volume 104, pp. 107-122. [CrossRef]

35. Ohlsson, A.; Hedlund, E.; Larsson, G. Examining the relationship between personality, organizational political skill and perceived team performance in a multinational military staff. J. Mil. Stud. 2016, 7, 24-30. [CrossRef]

36. Foster, D.P.; George, E.I. The Risk Inflation Criterion for Multiple Regression. Ann. Stat. 1994, 22, 1947-1975. [CrossRef]

37. Hurvich, C.M.; Tsai, C.L. Regression and Time Series Model Selection in Small Samples. Biometrika 1989, 76, 297-307. [CrossRef]

38. Cohen, J.; Cohen, P.; West, S.G.; Aiken, L.S. Applied Multiple Regression/Correlation Analysis for the Behavioral Sciences, 3rd ed.; Erlbaum: Mahwah, NJ, USA, 2003; pp. 151-190.

39. LeBreton, J.M.; Tonidandel, S. Multivariate relative importance: Extending relative weight analysis to multivariate criterion spaces. J. Appl. Psychol. 2008, 93, 329-345. [CrossRef]

40. Ennouri, K.; Ben, A.R.; Triki, M.A.; Ottaviani, E.; Mazzarello, M.; Hertelli, F.; Zouari, N. Multiple linear regression and artificial neural networks for delta-endotoxin and protease yields modelling of Bacillus thuringiensis. 3 Biotech 2017, 7, 187. [CrossRef]

41. Fradette, K.; Keselman, H.J.; Lix, L.; Algina, J.; Wilcox, R.R. Conventional and Robust Paired and Independent-Samples t Tests: Type I Error and Power Rates. J. Mod. Appl. Stat. Methods 2003, 2, 481-496. [CrossRef]

42. Abell, J.G.; Stalder, T.; Ferrie, J.E.; Shipley, M.J.; Kirschbaum, C.; Kivimäki, M.; Kumari, M. Assessing Cortisol from Hair Samples in a Large Observational Cohort: The Whitehall II Study. Psychoneuroendocrinology 2016, 73, 148-156. [CrossRef] [PubMed]

43. Skoluda, N.; Dettenborn, L.; Stalder, T.; Kirschbaum, C. Elevated Hair Cortisol Concentrations in Endurance Athletes. Psychoneuroendocrinology 2012, 37, 611-617. [CrossRef] [PubMed]

44. El Mlili, N.; Ahabrach, H.; Cauli, O. Hair Cortisol Concentration as a Biomarker of Sleep Quality and Related Disorders. Life 2021, 11, 81. [CrossRef]

45. Koumantarou Malisiova, E.; Mourikis, I.; Darviri, C.; Nicolaides, N.C.; Zervas, I.M.; Papageorgiou, C.; Chrousos, G.P. Hair Cortisol Concentrations in Mental Disorders: A Systematic Review. Physiol. Behav. 2021, 229, 113244. [CrossRef]

46. Dettenborn, L.; Tietze, A.; Bruckner, F.; Kirschbaum, C. Higher Cortisol Content in Hair among Long-Term Unemployed Individuals Compared to Controls. Psychoneuroendocrinology 2010, 35, 1404-1409. [CrossRef] [PubMed]

47. Van Uum, S.H.M.; Sauvé, B.; Fraser, L.A.; Morley-Forster, P.; Paul, T.L.; Koren, G. Elevated Content of Cortisol in Hair of Patients with Severe Chronic Pain: A Novel Biomarker for Stress. Stress 2008, 11, 483-488. [CrossRef]

48. Karlén, J.; Ludvigsson, J.; Frostell, A.; Theodorsson, E.; Faresjö, T. Cortisol in Hair Measured in Young Adults—A Biomarker of Major Life Stressors? BMC Clin. Pathol. 2011, 11, 12. [CrossRef] [PubMed] 
49. Taylor, M.K.; Sausen, K.P.; Potterat, E.G.; Mujica-Parodi, L.R.; Reis, J.P.; Markham, A.E.; Padilla, G.A.; Taylor, D.L. Stressful Military Training: Endocrine Reactivity, Performance, and Psychological Impact. Aviat. Space Environ. Med. 2007, 78, 1143-1149. [CrossRef] [PubMed]

50. Gifford, R.M.; O’Leary, T.J.; Double, R.L.; Wardle, S.L.; Wilson, K.; Boyle, L.D.; Homer, N.Z.M.; Kirschbaum, C.; Greeves, J.P.; Woods, D.R.; et al. Positive Adaptation of HPA Axis Function in Women during 44 Weeks of Infantry-Based Military Training. Psychoneuroendocrinology 2019, 110, 104432. [CrossRef] [PubMed]

51. North Atlantic Treating Organization, Science and Technology Organization. Military Suicide Prevention: Report Prepared for NATO Leadership; NATO/STO: Brussels, Belgium, 2018; pp. 77-82. Available online: https://www.sto.nato.int/publications/STO\% 20Technical\%20Reports /Forms/Technical\%20Report\%20Document\%20Set/docsethomepage.aspx?ID=4019\&FolderCTID= 0x0120D5200078F9E87043356C409A0D30823AFA16F6010066D541ED10A62C40B2AB0FEBE9841A61\&List=92d5819c-e6ec-42 41-aa4e-57bf918681b1\&RootFolder=\%2Fpublications\%2FSTO\%20Technical\%20Reports\%2FSTO-TR-HFM-218 (accessed on 10 November 2021).

52. Lennartsson, A.-K.; Kushnir, M.M.; Bergquist, J.; Jonsdottir, I.H. DHEA and DHEA-S Response to Acute Psychosocial Stress in Healthy Men and Women. Biol. Psychol. 2012, 90, 143-149. [CrossRef] [PubMed]

53. Qiao, S.; Li, X.; Zilioli, S.; Chen, Z.; Deng, H.; Pan, J.; Guo, W. Hair Measurements of Cortisol, DHEA, and DHEA to Cortisol Ratio as Biomarkers of Chronic Stress among People Living with HIV in China: Known-Group Validation. PLoS ONE 2017, 12, e0169827. [CrossRef] [PubMed]

54. Gomez-Merino, D.; Chennaoui, M.; Burnat, P.; Drogou, C.; Guezennec, C.Y. Immune and Hormonal Changes Following Intense Military Training. Mil. Med. 2003, 168, 1034-1038. [CrossRef] [PubMed]

55. Tsigos, C.; Kyrou, I.; Kassi, E.; Chrousos, G.P. Stress: Endocrine Physiology and Pathophysiology. In Endotext; Feingold, K.R., Anawalt, B., Boyce, A., Chrousos, G., de Herder, W.W., Dhatariya, K., Dungan, K., Grossman, A., Hershman, J.M., Hofland, J., et al., Eds.; MDText.com, Inc.: South Dartmouth, MA, USA, 2000.

56. van den Berghe, G. The Neuroendocrine Response to Stress Is a Dynamic Process. Best Pract. Res. Clin. Endocrinol. Metab. 2001, 15, 405-419. [CrossRef]

57. Michopoulos, V.; Norrholm, S.D.; Jovanovic, T. Diagnostic Biomarkers for Posttraumatic Stress Disorder: Promising Horizons from Translational Neuroscience Research. Biol. Psychiatry 2015, 78, 344-353. [CrossRef]

58. Reijnen, A.; Geuze, E.; Vermetten, E. The Effect of Deployment to a Combat Zone on Testosterone Levels and the Association with the Development of Posttraumatic Stress Symptoms: A Longitudinal Prospective Dutch Military Cohort Study. Psychoneuroendocrinology 2015, 51, 525-533. [CrossRef]

59. Elmi, A.; Galligioni, V.; Govoni, N.; Bertocchi, M.; Aniballi, C.; Bacci, M.L.; Sánchez-Morgado, J.M.; Ventrella, D. Quantification of Hair Corticosterone, DHEA and Testosterone as a Potential Tool for Welfare Assessment in Male Laboratory Mice. Animals 2020, 10, 2408. [CrossRef] [PubMed]

60. Quinn, T.; Greaves, R.; Badoer, E.; Walker, D. DHEA in Prenatal and Postnatal Life: Implications for Brain and Behavior. Vitam. Horm. 2018, 108, 145-174. [CrossRef] [PubMed]

61. Taylor, A.E.; Keevil, B.; Huhtaniemi, I.T. Mass Spectrometry and Immunoassay: How to Measure Steroid Hormones Today and Tomorrow. Eur. J. Endocrinol. 2015, 173, D1-D12. [CrossRef] [PubMed] 